\title{
Erythrodermic Manifestation due to Hyperinfestation of Scabies
}

\author{
Sandra Widaty, Martinus, Yenny Rachmawati \\ Department of Dermatology and Venereology, Faculty of Medicine Universitas Indonesia/Dr. Cipto \\ Mangunkusumo Hospital, Jakarta, Indonesia
}

\begin{abstract}
Background: Scabies is a highly contagious skin disease with various skin clinical presentations. In consideration of its clinical presentations, proper early-onset diagnosis of scabies may not be met, leading to mistreatment and more severe scabies, Norwegian (crusted) scabies. Purpose: To report a case of Norwegian scabies misdiagnosed as eczema in a previously immunocompetent patient. Case: A 32-year-old man was admitted with generalized erythematous skin rash, pruritic, and hyperkeratotic scales of the body. He was previously diagnosed with eczema two months ago and was prescribed both topical and systemic steroid. Skin scales worsened and kept expanding after the treatment. There was a family history of nocturnal itch. Dermoscopic and microscopic examination from skin lesion and scraping with potassium hydroxide revealed the signs of scabies infection. Discussion: Norwegian scabies could be prevented by the correct diagnosis at the early-onset of the disease. Misdiagnosis due to various skin clinical presentations, leading to mistreatment of the infection. In this case, family history plays a role that could elucidate the presence of scabies infection. Conclusion: A correct diagnosis and treatment for the early-phase scabies-infected patient will be beneficial for the patient to prevent hyperinfestation of scabies mites. Specific examination for scabies decreases the possibility of misdiagnosis.
\end{abstract}

Keywords: Norwegian scabies, Sarcoptes scabiei, erythroderma.

Correspondence: Sandra Widaty, Department of Dermatology and Venereology, Faculty of Medicine, Universitas Indonesia/Dr. Cipto Mangunkusumo Hospital, Gedung G5, J1. Diponegoro No. 71, Jakarta Pusat 10430, Indonesia. Phone: +6287878707048, email: sandra.widaty@gmail.com, sanwidaty@ui.ac.id.

\section{BACKGROUND}

Scabies is a highly contagious skin disease caused by the infestation of female ectoparasite called Sarcoptes scabiei..$^{1}$ The mites are mainly transmitted via direct skin-to-skin contact and less often transmitted via indirect contact through fomites. ${ }^{1,2}$ During scabies infection, the average number of adult female mites is between five to fifteen. ${ }^{1,3}$ However, in Norwegian (crusted) scabies a severe and atypical form of scabies, the number of mites can go up from thousands to millions in a single infected person. ${ }^{1,2}$

Norwegian scabies was first described among leprosy patients in Norway by Boeck and Danielssen in 1848. ${ }^{2}$ Norwegian scabies is characterized by erythematous hyperkeratotic skin crusts, irregular thickening, and skin fissuring full of mites and eggs; ${ }^{4,5}$ but atypical manifestations may occur, making Norwegian scabies hard to diagnose. ${ }^{6}$ Norwegian scabies commonly occurs in immunocompromised individuals with conditions such as lymphoma, Human Immunodeficiency Virus (HIV) infection, graftversus-host disease, malnutrition, and history of immunosuppressive therapy who fail to control the multiplication of the scabies mite in their skin., ${ }^{2,5,7}$
Unlike ordinary scabies infection, Norwegian scabies is highly contagious with a five-year mortality rate of up to $50 \%$.

\section{CASE REPORT}

A 32-year-old man with no previous history of chronic disease was admitted to our hospital's emergency department with generalized erythematous skin rash, pruritic, and hyperkeratotic scales of the body. Two months ago, the lesion started on the interdigital folds of the hands and feet. The lesion then slowly spread to other parts of the body, accompanied by moderate itch, which intensified during the night. Due to such complaints, he sought medical care and was diagnosed with eczema. He was prescribed with oral methylprednisolone $16 \mathrm{mg}$ ter in die (TID) and topical steroid treatment for two months. The ithcy sensation slightly reduced, but the skin scales worsened after the treatment. Family history revealed that his wife and son also had a nocturnal itch.

Physical examination revealed an unremarkable general condition. Extensive generalized erythematous plaques with large, warty crusts, irregular thickening, and hyperkeratotic scales were observed in the face, 
neck, trunk, arms, forearms, thighs, genitalia, gluteal region, dorsum of hands and feet, and webs of fingers (Figure 1). Dermoscopic examination result showed jetliner sign (Figure 2). Laboratory workup revealed leukocytosis, peripheral blood eosinophilia, elevated lactate dehydrogenase (LDH), elevated immunoglobulin-E (IgE), hypoalbuminemia, normal cortisol level, and serologically negative for HIV. The chest radiograph was unremarkable. Microscopic examination from the skin scraping dissolved in $20 \%$ potassium hydroxide $(\mathrm{KOH})$ revealed the presence of Sarcoptes scabiei mites (Figure 2). Dermoscopic examination supported the microscopic findings where the fore portion of the mites was found as multiple triangular or $\mathrm{V}$-shaped structure resembling a jetliner with its trail. Therefore, the patient was diagnosed with erythroderma due to Norwegian scabies.
The patient was treated with $5 \%$ permethrin cream twice a week for 4 weeks, $300 \mathrm{mg}$ clindamycin per oral (p.o.) TID, $10 \mathrm{mg}$ cetirizine p.o. quaque die (QD), normal saline wet dressing on crust and fissure area bis in die (BID), albumin transfusion, and tapered off dose of methylprednisolone. After two weeks of hospitalization, the patient showed significant clinical improvement. He was discharged and given $180 \mathrm{mg}$ mycophenolic acid BID. During the follow-up at our outpatient clinic, he mentioned the itchy sensation subsided along with the redness and skin lesions (Figure 3). Dermoscopic and microscopic examinations were done and the results were negative for the presence of scabies parasite. His family member was given $5 \%$ permethrin cream once a week for two weeks due to the history of nocturnal itch and highly contagious condition. No outbreak of scabies occurred among the hospital staff who treated the patients.

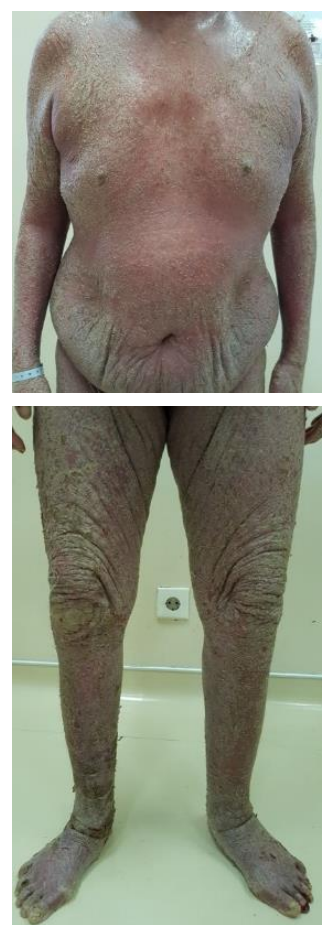

Figure 1. Generalized extensive erythema plaques, scales, irregular thickening, and keratinization were observed.
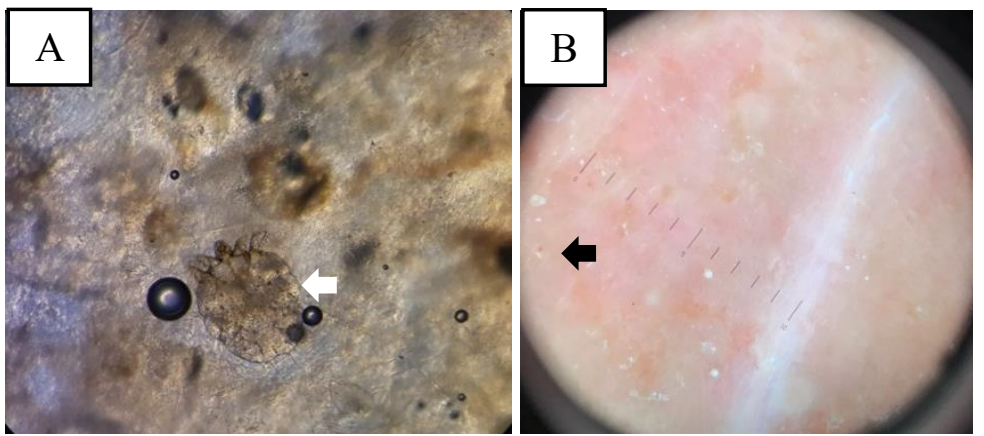

Figure 2. A. Dermoscopic examination showed a jetliner sign (black arrow). B. Microscopic examination of the skin scraping clarified with $20 \%$ potassium hydroxide $(\mathrm{KOH})$ showed the presence of adult mite (white arrow). 

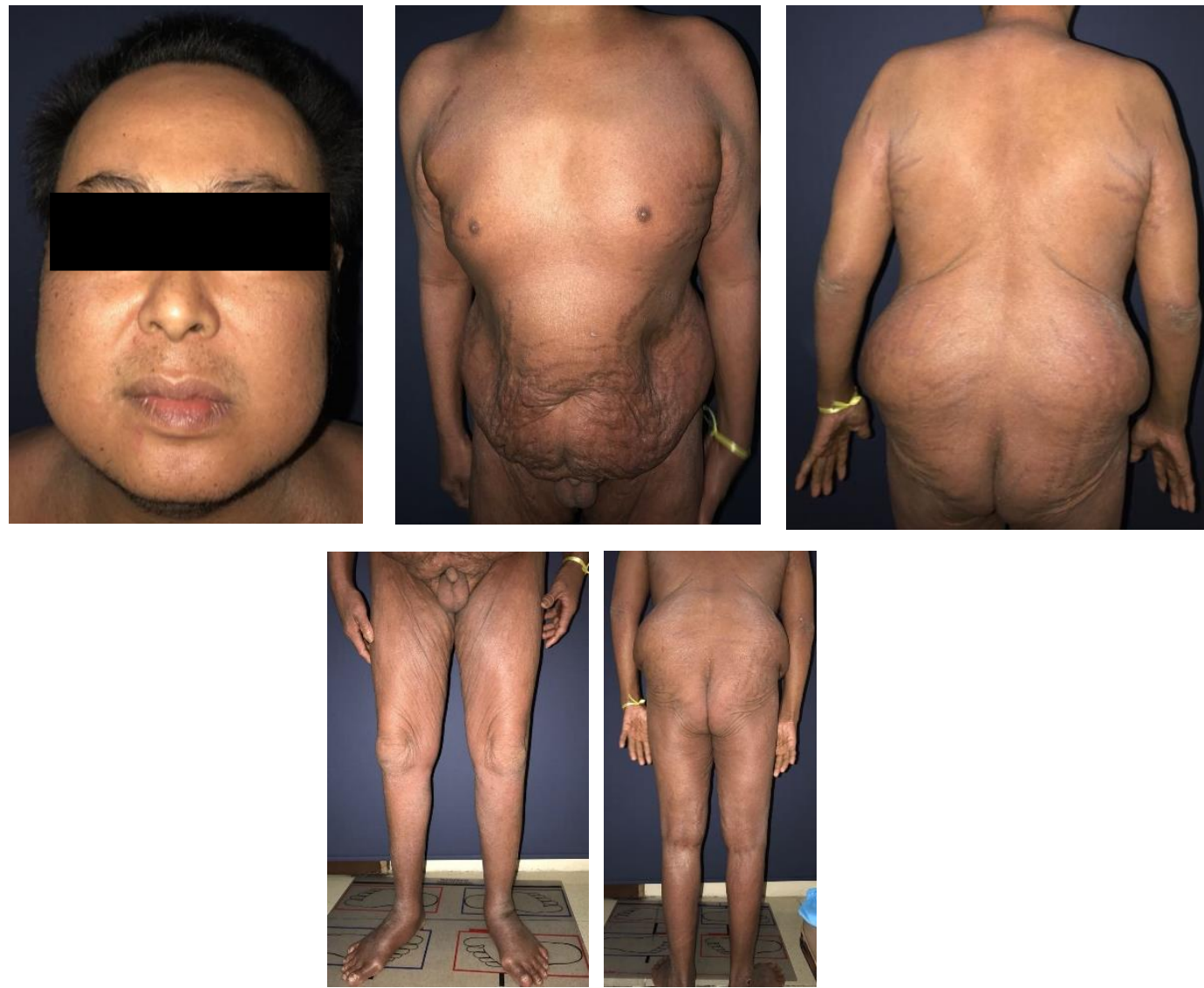

Figure 3. After four-weeks topical scabicidal treatment, clinical improvement was marked by reduced erythematous plaques, warty crusts, irregular thickening, fissuring, and scales.

\section{DISCUSSION}

Norwegian scabies is a rare but severe condition and highly contagious skin disease caused by parasite. This condition is usually associated with an immunocompromised state such as HIV/Aqcuired Immune Deficiency Syndrome (AIDS), malignancies, or immunosuppressive therapy., ${ }^{2,5,7}$ In this variant, scabies load can range from thousand to millions and exceedingly contagious. ${ }^{8,9}$ In our case, the development of Norwegian scabies could be prevented by the correct diagnosis at the early-onset of the disease. However, due to various skin clinical presentations, the diagnosis of scabies is often missed, which leads to mistreatment of the infection. ${ }^{2,6}$ To avoid misdiagnosis, we can use dermoscopy examination with its specific presentation of scabies infection, while microscopic examination revealed Sarcoptes scabies is still the gold standard..$^{10,11}$

Norwegian scabies is a rare cause of erythroderma (less than $0.5 \%$ cases) ${ }^{5}$ Scabies can be misdiagnosed as eczema without the presentation of mites. ${ }^{12,13}$ It can also be misdiagnosed as seborrheic dermatitis, atopic dermatitis, ichthyosis, and psoriatic erythroderma. Many of these differential diagnoses are treated with steroid, which will further be delayed the correct diagnosis. ${ }^{14,15}$ In this case, family history played a role that could elucidate the presence of scabies infection. Unfortunately, the patient was treated with high-potent topical corticosteroids over a long period of time which induced the immunosuppression state ascribed to the development of Norwegian scabies. Cases of Norwegian scabies after locally applied steroid in immunocompetent patients were reported before. ${ }^{16}$ Das et al. ${ }^{5}$ reported a case of erythroderma caused by Norwegian scabies in elderly of 62 years old who was previously diagnoses as eczema and psoriasis and treated with topical corticosteroid. Ebrahim et $\mathrm{al}^{2}$ also reported a rare case of non pruritic erythroderma caused by Norwegian scabies in a immunocompetent 19 years old patient. Both cases had the lesions sparing palmoplantar area.

Due to a large number of scabies mites in the epidermis and the hyperkeratotic skin, Norwegian scabies can be challenging to treat. Repeated application of topical/systemic scabicidal agents is required to treat the condition. ${ }^{2}$ Previous case reports of Norwegian scabies were treated using weekly oral ivermectin. ${ }^{2,5}$ In our case, the treatment with topical scabicidal agents ( $5 \%$ permethrin) accompanied by antibiotics for secondary infection, antihistamine to 
reduce the itch, and tapered off the dose of the corticosteroid were able to clear the parasite infestation and reduce the skin symptoms.

Other than treating the patient, all persons in contact with patient should be treated for scabies irrespective of symptoms. ${ }^{5}$ Patients should also be educated to improve their personal hygiene such as not sharing clothing, bedding and towels. Linen and clothing should be washed using hot water and hot dryer while items that cannot be washed should be put in a closed plastic bag for several days. Enviromental management such as routine cleaning and vacumming of furniture should be couraged. This preventive meassures are important to stop scabies transmission. ${ }^{17,18}$

In conclusion, we reported a case of Norwegian scabies with a history of corticosteroid treatment due to early misdiagnosis as eczema in a previously immunocompetent patient.

\section{REFERENCES}

1. Banerji A; Canadian Paediatric Society, First Nations, Inuit and Métis Health Committee. Scabies. Paediatr Child Health 2015; 20(7): 395 402.

2. Ebrahim KC, Alves JB, Tome LA, Moraes CF, Gaspar AD, Franck KF, et al. Norwegian scabies - rare case of atypical manifestation. An Bras Dermatol 2016; 91(6): 826-8.

3. Leung V, Miller M. Detection of scabies: a systematic review of diagnostic methods. Can J Infect Dis Med Microbiol 2011; 22(4): 143-6.

4. Davis JS, McGloughlin S, Tong SYC, Walton SF, Currie BJ. A novel clinical grading scale to guide the management of crusted scabies. PLoS Negl Trop Dis 2013; 7(9): e2387.

5. Das A, Bar C, Patra A. Norwegian scabies: rare cause of erythroderma. Indian Dermatol Online J 2015;6(1):52-4.

6. Cohen PR. Scabies masquerading as bullous pemphigoid: scabies surrepticius. Clin Cosmet Investig Dermatol 2017; 10: 317-24.

7. Bu X, Fan J, Hu X, Bi X, Peng B, Zhang D. Norwegian scabies in a patient treated with
Tripterygium glycoside for rheumatoid arthritis. An Bras Dermatol 2017; 92(4): 556-8.

8. Aukerman W, Curfman K, Shayesteh K. Norwegian Scabies management after prolonged disease course: a case report. Int J Surg Case Rep 2019; 6: 180-3.

9. Burns P, Yang S, Strote J. Norwegian scabies. West J Emerg Med 2015; 16(4): 587-90.

10. Diab HM. Scabies incognito: diagnostic value of dermoscopy-guided microscopic examination. J Egypt Women Dermatol Soc 2017; 14: 56-60.

11. Walter B, Heukelback J, Fengler G, Worth C, Hengge $U$, Feldmeier $H$. Comparison of dermoscopy, skin scraping, and the adhesive tape test for the diagnosis of scabies in a resource-poor setting. Arch Dermatol 2011; 147: 468-73.

12. Leung V, Miller M. Detection of scabies: a systematic review of diagnostic methods. Can J Infect Dis Med Microbiol 2011; 22(4): 143-6.

13. Das A, Bar C, Patra A. Norwegian scabies: rare cause of erythroderma. Indian Dermatol Online J 2015; 6(1): 52-4.

14. Lima FCDR, Cerqueira AMM, Guimarães MBS, Padilha CBS, Craide FH, Bombardelli M. Crusted scabies due to indiscriminate use of glucocorticoid therapy in infant. An Bras Dermatol 2017; 92(3): 383-85.

15. Sandre M, Ralevski F, Rau N. An elderly longterm care resident with crusted scabies. Can J Infect Dis Med Microbiol 2015; 26(1): 39-40.

16. Binic I, Jankovic A, Ljubenovic M. Crusted (Norwegian) scabies following systemic and topical corticosteroid therapy. J Korean Med Sci 2010; 25(1): 188-91.

17. Center for Disease Control and Prevention. Parasites - Scabies: Prevention \& Control [serial on internet]. 2018 [cited April 22 2021]. Available from:

https://www.cdc.gov/parasites/scabies/prevent.ht $\mathrm{ml}$

18. Shimose L, Munoz-Price LS. Diagnosis, prevention, and treatment of scabies. Curr Infect Dis Rep 2013;15(5): 426-31. 